\title{
Escola e Formação para a cidadania: qual o papel da Educação Física?
}

\author{
Flávio Cremasco Ferreira* \\ Lino Castellani Filho**
}

\begin{abstract}
Resumo: Este artigo pretende discutir a questão da cidadania, tão em pauta nos últimos anos, especialmente no que se refere a sua relação com a educação. Apresenta uma visão crítica tanto do entendimento sobre o termo cidadania, quanto desta relação com a educação, feita, por vezes, de forma irrefletida. Tomando como base essa discussão, pretende construir reflexões iniciais sobre a possibilidade da educação física, enquanto componente curricular obrigatório das escolas brasileiras, de contribuir na tão propalada e buscada formação do cidadão.
\end{abstract}

Palavras-chave: Cidadania. Educação. Educação Física.

\section{INTRODUÇÃO'}

O ano de 1988 foi muito importante para o Brasil. Depois de oitenta anos do século XX marcados por diversas mudanças e reviravoltas no campo político, o país havia reconquistado o direito ao voto direto e, pouco adiante, elaborava e aprovava uma nova constituição, que se convencionou chamar de Cidadã. Os esforços de Ulysses Guimarães e muitos outros que estiveram envolvidos resultaram em um texto que pretendia e previa muitos avanços para o país, mas parte deles ainda não se materializou até os dias de hoje.

\footnotetext{
"Programa de Pós-graduação em Educação Física. Faculdade de Educação Física. Unicamp. Bolsista CNPQ/Capes. Universidade Estadual de Campinas. Campinas, SP, Brasil. E-mail: flavio.cremasco@gmail.com

"Doutor em Educação; Professor-Visitante da UNB; Professor Livre-Docente da Unicamp (1986/11); Pesquisador-líder do Observatório do Esporte - Observatório de Políticas de Educação Física, Esporte e Lazer (CNPq/Unicamp). "A participação na qualidade de co-autor reflete o entendimento convencionado pelo campo acadêmico sobre o conceito ampliado de orientação". 'Este artigo está baseado na dissertação elaborada pelo autor, sob orientação do co-autor, e apresentada ao programa de pós-graduação da Faculdade de Educação Física da Universidade Estadual de Campinas - UNICAMP, para fins de obtenção do título de mestre.
} 
A partir deste momento histórico, o termo cidadania foi ganhando cada vez mais importância, sendo proclamado nos mais diversos âmbitos. "Cidadão" se tornou palavra de ordem nos discursos políticos, nos documentos oficiais dos governos, nas propostas do terceiro setor, no discurso da mídia e da maioria dos brasileiros.

Não demorou muito para que, sob influência de um sentimento que Jorge Nagle (1974) tão bem traduz - o entusiasmo pela educação, entendida como panaceia para todos os males - a propalada "formação do cidadão" fosse levada para dentro dos muros da escola. É notório que, cada vez mais, seja através de documentos oficiais de âmbito federal, estadual ou municipal, ou através da propaganda das escolas $\mathrm{p}$ articulares, a escola tem sido chamada a cumprir o papel de deflagradora, garantidora da formação cidadã dos indivíduos.

Cidadania foi se tornando assim uma palavra com cara e efeito de ponto final. De tão alardeada e repetida, seu valor e importância ganhou status indiscutível. É o norte que move os muitos anos de ensino no Brasil. Mas os dados de 2009 do Inaf (Indicador de Alfabetismo Funcional) mostram que quase um em cada quatro brasileiros sai do ensino fundamental sem saber ler ou escrever bem ( $24 \%$ são analfabetos funcionais) - cidadãos?

Segue-se então para o Ensino Médio, onde se revela uma mais que evidente valorização do ensino técnico ou tecnológico, devido ao vertiginoso aumento no número de instituições e cursos desse tipo. Apenas na rede federal de educação profissional há, segundo o MEC, um investimento de $\mathrm{R} \$ 1,1$ bilhão na expansão da rede. $\mathrm{O}$ número de escolas saltou de 140 em 2002, para atuais 354, disponibilizando mais de 400 mil vagas em todo o Brasil. A previsão, ainda segundo o Ministério, é entregar mais 208 unidades até o final de 2014, o que totalizaria mais de 600 mil vagas na rede federal de educação profissional, científica e tecnológica.

Nestes cursos voltados para a formação profissional, há uma evidente preocupação com a adequação e preparação do indivíduo para o mercado de trabalho, dando ao Ensino Médio um carácter terminal e não de "meio", ponte de preparação para outro e 
complementar nível de ensino (o superior). Vale refletir quais serão os brasileiros que ocuparão as vagas desses cursos tecnológicos, e quais terão a possibilidade de não apenas alcançar níveis mais avançados de conhecimento, como também, através da pesquisa nas instituições de nível superior de ensino, elaborar novas formas de intervir na sociedade. Quem se ocupará de construir a sociedade do futuro, e a quem caberá apenas rodar suas engrenagens?

Tais constatações, contudo, não nos desanima sobre o termo. A cidadania, bem entendida como possibilidade efetiva de participação, de todos os indivíduos, nos diversos âmbitos da sociedade, é uma bandeira que consideramos de fundamental importância. Contudo, não é raro que um dado termo acabe perdendo grande parte, quando não todo, de seu verdadeiro significado se exaustivamente usado e repetido.

Sendo assim, este artigo buscará, inicial e brevemente, compreender melhor os significados que carrega o termo cidadania, entendendo-o como um conceito em constante mutação, uma vez que histórico e construído e re-significado pelo ser humano. Dialogando com alguns autores que se debruçaram sobre o tema, pretende-se refletir sobre esse conteúdo, que acreditamos perdido, do conceito de cidadania.

Em seguida, buscamos entender a tão constante relação que se faz entre a educação e a cidadania. Sem a intenção de esclarecer as origens históricas dessa relação, priorizamos o questionamento sério e crítico sobre ela. Pretende-se ir além da atual associação, feita muitas vezes de forma direta e não refletida, entre a instituição escolar e a formação do cidadão, discutindo se seria ela realmente capaz de garantir a cidadania.

Por fim, seria então o momento de partir em busca de respostas para a questão motivadora deste trabalho: ora, se a cidadania está sempre associada à educação, seria a educação física, componente curricular obrigatório das escolas brasileiras, capaz de contribuir para o processo de desenvolvimento do aluno cidadão? 


\section{A QUESTÃo dA CIDADANIA - UMA BREVE ABORDAGEM}

Dentre os estudos sobre cidadania, um dos mais notórios e reconhecidos dentro da área das humanidades é aquele produzido por T. H. Marshall em 1963 (publicado no Brasil em 1967). Citados por diversos outros autores, Marshall construiu uma base de análise sobre o termo que consideramos bastante interessante. A citação a seguir é central em sua tese:

A cidadania é um status concedido àqueles que são membros integrais de uma comunidade. Todos aqueles que possuem o status são iguais com respeito aos direitos e obrigações pertinentes ao status. Não há nenhum princípio universal que determine o que estes direitos e obrigações serão, mas as sociedades nas quais a cidadania é uma instituição em desenvolvimento criam uma imagem de uma cidadania ideal em relação à qual o sucesso pode ser medido e em relação à qual a aspiração pode ser dirigida. (MARSHALL, 1967, p. 76).

A grande contribuição do autor nesse trecho é colocar a cidadania como algo vivo e constantemente passível de transformação e mudança. Impossível de ser mensurada através de um medidor universal, a cidadania seria uma ideia, uma construção social, um conjunto de comportamentos que caracterizariam o cidadão, ao mesmo tempo em que marginalizariam aqueles que não apresentassem essa conduta (seja por falta de interesse, seja por falta de possibilidade).

Outra construção de Marshall, que se revelou base para todos os autores aqui trabalhados, foi sua divisão da cidadania em três âmbitos: os direitos civis, os direitos políticos e os direitos sociais.

O elemento civil é composto dos direitos necessários à liberdade individual - liberdade de ir e vir, liberdade de imprensa, pensamento e fé, o direito à propriedade e de concluir contratos válidos e o direito à justiça. [...] as instituições mais intimamente associadas com os direitos civis são os tribunais de justiça. Por elemento político, se deve entender o direito de participar no exercício do poder político, 
como um membro de um organismo investido da autoridade política ou como um eleitor dos membros de tal organismo. As instituições correspondentes são o parlamento e conselhos do Governo local. O elemento social se refere a tudo o que vai desde o direito a um mínimo de bem-estar econômico e segurança ao direito de participar, por completo, na herança social e levar a vida de um ser civilizado de acordo com os padrões que prevalecem na sociedade. As instituições mais intimamente ligadas com ele são o sistema educacional e os serviços sociais. (MARSHALL, 1967, p. 63-64).

Para o autor, tal divisão se justifica por questões históricas, mais do que pela lógica. Ou seja, para Marshall, os direitos civis teriam sido os primeiros a surgirem, permanecendo até hoje bastante semelhantes à sua formulação original na primeira Lei de Reforma, de 1832. Em seguida, o surgimento e ampliação dos direitos políticos teria sido a grande pauta do século XIX, ainda que tenham se universalizado apenas em 1918. Por fim, os direitos sociais, ainda que não tenham de fato surgido apenas depois dos outros (haveria diversas formas de manifestações de reconhecimento de direitos sociais em outras épocas), teriam atingido o mesmo nível de reconhecimento e importância apenas no século XX.

Reconstruída aqui, de forma bastante breve, o entendimento de Marshall sobre a cidadania, vale destacar seu posicionamento crítico quanto ao uso do termo no modelo de produção capitalista. Para o autor:

[...] o contrato moderno é essencialmente um acordo entre homens que são livres e iguais em status, embora não necessariamente em poder. $\mathrm{O}$ status não foi eliminado do sistema social. O status diferencial, associado com classe, função e família, foi substituído pelo único status uniforme de cidadania que ofereceu o fundamento da igualdade sobre a qual a estrutura da desigualdade foi edificada. (MARSHALL, 1967, p. 79-80, grifo nosso).

A reflexão de Marshall recai sobre o "direito" como máscara eficiente para disfarçar a desigualdade. $\mathrm{O}$ autor questiona, por 
exemplo, o fato de que o direito à propriedade não é efetivamente o direito de possuí-la, mas sim de comprá-la se puder. Também nessa linha reflexiva, o autor fala sobre a tão vangloriada liberdade de expressão, que afinal teria pouca importância se, por ignorância, uma pessoa tivesse pouco a dizer e nenhuma forma de se fazer ouvir.

Transportar essa análise de forma direta para outros contextos seria contraditório com a própria visão de seu autor. Marshall trata aqui da Inglaterra onde viveu, e a análise que constrói se baseia nesse país de história bastante singular, muitas vezes motor central das mudanças do mundo. No Brasil, a formatação histórica é extremamente distinta.

É por tanto que as reflexões do pesquisador José Murilo de Carvalho parecem bastante acertadas. Para o autor:

[...] houve no Brasil pelo menos duas diferenças importantes (se compararmos o processo de desenvolvimento da cidadania aqui com o modelo inglês, estudado por Marshall). A primeira referese à maior ênfase em um dos direitos, o social, em relação aos outros. A segunda refere-se à alteração na sequência em que os direitos foram adquiridos: entre nós, o social precedeu os outros. (CARVALHO, 2010, p. 11-12).

Para o autor, uma série de conformações históricas (muito bem esclarecidas em seu "Cidadania no Brasil: o longo caminho"), teriam levado o Brasil a desenvolver primeiro os direitos sociais. Isso teria desencadeado um processo que acabou por fazer com que a população brasileira os enxergassem não como tal - direito - mas sim como um atencioso presente do governo, a quem deveriam prestar gratidão e lealdade. Ora, a noção de cidadania que aqui se conforma é "passiva e receptora antes que ativa e reivindicadora" (CARVALHO, 2010, p. 126).

Outro autor brasileiro que discute de forma muito consistente a questão da cidadania é Pedro Demo. Em seu livro Cidadania Tutelada e Cidadania Assistida, define o termo como "[...] 
competência humana de fazer-se sujeito, para fazer história própria e coletivamente organizada" (DEMO,1995,p. 1). Percebe-se, nessa definição, a colocação do indivíduo na posição central da sociedade. É dele, e a partir dele, que se constroem todas as relações, bem como o mundo a sua volta.

Pedro Demo utiliza três tipos de cidadania em suas análises: a cidadania tutelada, a assistida e a emancipada. A cidadania tutelada seria aquela marcadamente cultivada, ou suportada, pela elite econômica e política, em que não ocorre suficiente consciência crítica e competência para abalar a tutela (DEMO, 1995). O resultado desse tipo de cidadania seria a reprodução indefinida da mesma elite histórica.

Cidadania assistida, construída de forma pouco diferente da tutelada, permitiria certa elaboração de algo que Demo chama de "embrião da noção de direito", mas o direito requisitado e defendido aqui é o da assistência, e não o da emancipação. Sendo assim, essa forma de cidadania também atua na reprodução da pobreza política e da desigualdade de oportunidades.

Enfim, "cidadania emancipada" é o termo proposto por Demo para caracterizar a cidadania que defende, definida como "competência essencial humana [...] de fazer-se sujeito, negando aceitar-se como objeto" (DEMO, 1995, p. 133). Para o autor, aquele que não atinge tal cidadania acaba por ser excluído da sociedade sem se aperceber disso, aceita a injustiça sem reagir e permanece massa de manobra, como se ser manipulado pela elite fosse apenas condição histórica, e não o embate constante de forças.

Para contribuir em posicionamento que aparecerá no parágrafo seguinte, vale destacar brevemente a dissertação de mestrado, defendida em 1981, por Eloisa Hofling que traz interessante consideração sobre "participação", ao apropriar-se das reflexões do pesquisador italiano Pizzorno. Sobre a possibilidade de um indivíduo fazer-se sujeito, como defende Demo, Hofling vai dizer que existe uma relação bastante direta entre a posição social de um indivíduo e suas efetivas possibilidades de participação política. Para a autora, 
baseada em Pizzorno, uma elevada posição social garante um sentimento mais efetivo de integração na sociedade, e é esse sentimento de integração que invoca o interesse na participação (além de garantir maiores chances de participação). Ou seja, a participação política estaria intimamente relacionada à posição social do indivíduo.

Demarca-se assim um distanciamento do pensamento de Pedro Demo. Através do apresentado de Marshall, e agora Hofling, podese perceber que a cidadania de Demo é individualizada, ou seja, se atenta muito ao indivíduo e a sua condição de cidadão tutelado, assistido ou emancipado. Sendo assim, muitas de suas ideias e propostas se dedicam ao indivíduo, no sentido de "educá-lo", emancipá-lo, entregar a ele as condições de se tornar cidadão, desconsiderando, ou talvez apenas diminuindo, o aspecto social e coletivo da cidadania enquanto condição relacionada e fundamentada na luta de classes.

Essa ressalva que fazemos em muito se relaciona a um processo em marcha atualmente, segundo Evelina Dagnino (2005), que envolve o pensamento neoliberal. Para a autora, dentro da atual crise latinoamericana (sobre a qual ela discorre em seu artigo) haveria uma crise discursiva, que por sua vez seria resultado de uma "confluência perversa", entre a lógica neoliberal e o projeto democratizante e participativo. Dagnino acredita que alguns pontos defendidos por ambos, mas compreendidos de forma diversa entre os dois grupos, têm provocado um deslocamento de sentido de, principalmente, três noções: sociedade civil, participação e cidadania. Ou seja, o vocabulário comum acabaria por obscurecer distinções e divergência entre as concepções desses dois grupos.

"[...] a noção de cidadania oferece talvez o caso mais dramático desse processo de deslocamento de significado" (DAGNINO, 2005, p. 55). Para a autora, o neoliberalismo vai construir uma noção de cidadania resumida a um "[...] conjunto de procedimentos". A noção coletiva de cidadania acaba individualizada. Aproxima-se cidadania e mercado, e o cidadão passa a ser o indivíduo integrado individualmente ao mercado, seja como produtor ou, especialmente, como consumidor. 


\section{DisCUTINDO A RELAÇÃo ENTRE EDUCAÇÃo E CIDADANIA}

A justificativa primeira para se buscar o debate sobre a relação entre educação e cidadania, consta na já citada Constituição Federal de 1988 que declara em seu artigo 205, "[...] a educação, direito de todos e dever do Estado e da família, será promovida e incentivada com a colaboração da sociedade, visando ao pleno desenvolvimento da pessoa, seu preparo para o exercício da cidadania e sua qualificação para o trabalho" (BRASIL, 1988).

Mesmo já sendo possível atinar para o fato de que "preparar para a cidadania" pode ter muitos significados, uma vez que se pode definir cidadania de diversas formas, o texto constitucional deixa claro que a instituição escolar, enquanto âmbito fundamental para a educação dos indivíduos trata da questão da cidadania.

Vários autores discutem essa relação, ainda que não como assunto específico de sua pesquisa. Benevides, por exemplo, escreve em texto publicado na revista Lua Nova, que "[...] não resta dúvida de que a educação política - entendida como educação para cidadania ativa - é o ponto nevrálgico da participação popular" (BENEVIDES, 1994, p.10). A autora, por tanto, coloca a educação como caminho central e fundamental para a construção da cidadania (participação). Defende ainda que essa educação deva se proceder na prática, "aprende-se a votar, votando", e com isso expande os espaços de aprendizagem da cidadania para além da escola.

No texto "A Escola e A Construção da Cidadania", de Antônio J. Severino, o autor coloca "a educação enquanto eventual mediação para a cidadania" (SEVERINO, 1992, p. 9). Nesse sentido, se a escola é espaço para o "aprendizado" da cidadania, Severino deixa claro que ela, contudo, não se encerra no ambiente escolar, mas deve ser ali desenvolvida para que possa ser exercida fora. $\mathrm{O}$ autor, que entende cidadania como uma "qualificação da condição da existência dos homens" (SEVERINO, 1992, p. 10), compartilha nesse texto suas dúvidas se a escola estaria realmente apta a contribuir para essa "qualidade existencial", se ela tem mesmo sido espaço para a construção da cidadania. 
Mas é Miguel Arroyo que, dentre os autores estudados, trata de maneira mais profunda, e também mais interessante, a relação educação - cidadania. No texto "Educação e Exclusão da Cidadania" (ARROYO; BUFFA; NOSELLA, 2000), o autor questiona essa relação, que é feita de forma tão imediata e sem questionamento pela população e mesmo por alguns acadêmicos da área.

Para Arroyo, o pensamento e a prática política sempre estiveram marcados por uma ideia de despreparo das camadas populares para a cidadania, para a participação. Seria então a educação a responsável pelo "treino" das habilidades necessárias à cidadania. Mas o autor destaca a importância de não se perder de vista o momento histórico em que nasce a relação entre educação, cidadania e participação: para ele, esse momento é aquele em que se fazia necessária uma massa de trabalhadores disponíveis, livres para o mercado que então ganhava espaço da agricultura. Ou seja, "os súditos tinham que ser feitos cidadãos livres para a participação na cidade, no novo convívio social" (ARROYO; BUFFA; NOSELLA, 2000, p. 38). Para o autor, passar por alto dessa "lógica global e dos efeitos reais que ela legitimou e continuar defendendo a educação como o ritual sagrado de passagem para o reino da liberdade é uma forma de contribuir para que a cidadania continue a ser negada, reprimida e protelada" (ARROYO; BUFFA; NOSELLA, 2000, p. 40).

A questão central para Arroyo é encontrar e, mais do que isso, explicitar para os profissionais da educação e as camadas populares, os verdadeiros determinantes sociais e econômicos para a exclusão da cidadania. Enquanto esses determinantes permanecerem escondidos sob as tantas teorias pedagógicas tradicionais, novas, novíssimas, não se poderá "fazer da luta pela educação uma expressão da participação e da cidadania" (ARROYO; BUFFA; NOSELLA, 2000, p. 41).

Para o autor, a cidadania "não é uma questão pedagógica, mas uma questão política [...] Reduzir a questão da cidadania dos trabalhadores a uma questão educativa é uma forma de ocultar a questão de base" (ARROYO; BUFFA; NOSELLA, 2000, p. 47). 
De certo, e como o próprio autor trata, essa crença profunda na educação como meio para a cidadania não será abandonada, e voltará sob diversas formas, sendo continuamente "[...] recitada às camadas populares como um santo remédio para sua constituição como cidadão" (ARROYO; BUFFA; NOSELLA, 2000, p. 52). Acreditamos que este sonho da transformação através da razão, do conhecimento, se mantém firme nos depoimentos e manifestos de muitos, desde acadêmicos até pais, professores, governantes. Constitui, enfim, uma lógica ainda dominante na sociedade.

$\mathrm{O}$ autor compartilha ainda um questionamento, que fazemos também nosso:

[...] resulta ingênuo sonhar com uma democracia e cidadania por conta-gotas: esperar que cada membro do corpo social vá sendo preparado e educado para entrar num convívio onde é esperado de braços abertos como sujeito de direitos. Até quando as ciências da educação se prestarão a esse jogo? (ARROYO; BUFFA; NOSELLA, 2000, p. 62).

Sem que isso signifique um abandono da educação, as questões que Arroyo levanta, e que compartilhamos, parecem pertinentes aos que buscam novas formas de se pensar a educação, especialmente no que se refere à sua relação com a cidadania, a fim de chegar a construções sociais mais dignas e igualitárias. Como o próprio autor escreve, "a educação não é uma precondição da democracia e da participação (e da cidadania), mas é parte, fruto e expressão do processo de sua constituição" (ARROYO; BUFFA; NOSELLA, 2000, p. 79).

\section{A cidadania e a Educação Físıca}

Ao nos aproximarmos enfim da Educação Física, percebemos que poucas vezes ela foi diretamente associada à questão da cidadania. Em uma rápida busca de textos que apresentassem em seu título ou entre as palavras-chave os termos "cidadania" e "educação física", foi possível encontrar poucos trabalhos. Contudo, 
se tal associação direta é pouco evidente, pode-se perceber que ao longo da história da educação física no Brasil construiu-se uma relação velada entre a educação física e determinadas visões de cidadania. Tal relação pode ser extraída através de um olhar atento à obra de Lino Castellani Filho, "Educação Física no Brasil: a história que não se conta", que tomará posição central mais adiante neste artigo.

Dos poucos textos encontrados na busca acima referida, a maioria se debruça, especificamente, sobre a relação do esporte com a cidadania, que não é o interesse central deste trabalho. Isso porque, ainda que haja um entendimento hegemônico de que, de fato, esporte na escola e educação física sejam sinônimos, a concepção para essa disciplina escolar aqui defendida é aquela proposta em 1992 pelo Coletivo de Autores, que entende ser ela responsável pelo trato pedagógico da cultura corporal: conjunto de atividades corporais construídas pelo homem, historicamente, em resposta a suas mais diversas necessidades e questionamentos. Tal obra também será destacada nas conclusões deste trabalho.

Foi ainda possível perceber nos textos lidos que poucos se aprofundam na questão da cidadania. Isso se justifica, em alguns, por serem trabalhos iniciais e de tamanho bastante reduzido, e em outros por conceber cidadania simplesmente como acesso a direitos. Além disso, alguns desses trabalhos, ainda que colocando o termo cidadania em destaque, pouco ou nada tratam do assunto ao longo do texto.

Com essa breve justificativa, revelamos nossa opção neste artigo de dar destaque à relação que chamamos de "velada" entre cidadania e educação física, através de breve incursão pelo histórico da área.

Na referencial obra de Castellani Filho, logo na introdução, o autor apresenta o objetivo do trabalho: desvelar, descortinar, a fim de melhor entender, a Educação Física e sua função ao longo da história. Tal processo se justifica pela busca de um entendimento oculto, que vá além do óbvio, do dito, do já demonstrado. Isso porque, conforme o autor evidencia já no título, há uma história que não vem sendo contada e que precisa ser revelada. 
O que nos conta Castellani Filho é que a educação física teve seu surgimento e desenvolvimento inicial muito atrelado ao âmbito militar. Através de dados históricos, comprova que foram os militares que assumiram para si a responsabilidade por organizar, definir e estruturar os primeiros cursos da área. Mas a preocupação de Lino não é comprovar essa evidente relação, mas buscar os significados dela.

Tal busca encontra consideração fundamental no fato de terem sido as escolas militares o espaço principal de assimilação e defesa da filosofia positivista. Segundo Castellani Filho, a situação do Brasil à época necessitava de uma filosofia clara e contundente, e foi nas ideias de Comte que os militares encontraram suas respostas. E na educação física escolar, o caminho para a produção do indivíduo vigoroso, forte, saudável e produtivo, capaz de contribuir no plano de desenvolvimento do país que permanecera tanto tempo na condição atrasada de colônia. O ímpeto pelo progresso do país vai levar os militares à busca da modelação de corpos aptos para tal tarefa.

Mas, como também aponta Castellani Filho, não foram os militares os únicos, talvez nem os principais, responsáveis pelo entendimento da Educação Física como educação do físico. Atuam nesse processo os médicos que, baseados em uma filosofia higienista, vão se colocar como os profissionais mais aptos para a conformação e construção do "novo" corpo saudável dos brasileiros, para a construção de um novo Brasil. São eles que vão trabalhar buscando "redefinir os padrões de conduta física, moral e intelectual da 'nova' família brasileira" (CASTELLANI FILHO, 1988. p. 39)².

É sob essa dupla influência que a batalha pela presença da Educação Física nas escolas se inicia. Nesse período, quando se constrói a base para o entendimento de sua função e utilidade, que se estende desde a segunda metade do século XIX até as décadas iniciais do século XX, elabora-se também um determinado entendimento sobre cidadão: indivíduo apto e adequado às exigências

${ }^{2} \mathrm{~A}$ referida obra está, atualmente, em sua 19ạ reimpressão.

Movimento, Porto Alegre, v. 18, n. 04, p. 135-154, out/dez de 2012. 
nacionais. Ou seja, num país ainda há pouco imperial, e feito república por meio de acordos e barganhas, a noção de país, de nação, ainda era extremamente fraca.

A disciplina militar e a eugenia médica constroem então uma determinada visão de cidadão: forte, saudável, dócil e eficaz; e é esse cidadão que será buscado. A repetição infindável dos movimentos calistênicos, a defesa, megalomaníaca, de educação física obrigatória para todos os residentes do Brasil (CASTELLANI FILHO, 1988. p. 74), a desobrigação das mulheres com prole, entre outras medidas e inciativas, vão moldar a educação física para a busca do cidadão desejado (e se isso era feito na época, por que não considerar possível transformar a educação física dos dias atuais para a busca de outro determinado tipo de cidadão?).

Aos poucos a situação política, econômica e social do Brasil vai se alterando, e a educação começa a ganhar também outro significado. Mesmo considerando, sempre, que a história não apresenta rupturas bem delineadas, mas sim um grande emaranhado de acontecimentos que se prolongam uns sobre os outros, é possível perceber que, com o aumento da população dos centros urbanos, começa a nascer uma outra preocupação para a educação física: o tempo de não trabalho.

Começou-se a perceber que o tempo livre de trabalho do trabalhador (aquele que não passa trabalhando ou recuperando as forças para o trabalho) também poderia ser momento interessante para a transmissão de ideologia. E mais uma vez a atividade física, e aqui especialmente o esporte, é convocado para organizar o tempo livre do trabalhador, uma vez que seria capaz de não apenas divertir e melhorar a saúde dos operários, como também contribuir admiravelmente para transmissão do princípio da unidade da empresa, ou seja, a união necessária para a vitória no esporte era transplantada para a fábrica. Assim o esporte no tempo de não trabalho (importante área de pesquisa na educação física, o lazer) foi requisitado para também colaborar na transmissão da ideologia neoliberal e dos preceitos necessário ao desenvolvimento capitalista do Brasil na primeira metade do século XX. 
E se os tempos vão mudando, os problemas que se apresentam, infelizmente, pouco se modificam. Afinal, se no início do período republicano a questão era livrar o Brasil do atraso causado pelo período colonial, agora, e desde a fundação do Estado Novo, o objetivo é livrar-se do subdesenvolvimento. Não é de se estranhar, por tanto, que as mesmas armas sejam usadas, sempre "adaptadas aos tempos atuais".

A tristeza em ver a educação física e o esporte atrelados, cúmplices de tão graves delitos (como o fatídico efeito catártico da conquista da Copa do Mundo de 1970) deve nos servir de motivação para uma luta constante e inquieta pela transformação da educação física escolar, na busca de torná-la ferramenta que contribua na construção de uma sociedade mais justa, livre e igualitária. Palavras de ordem que não podem ser consideradas vazias pelo simples fato de terem sido muito usadas, mas que precisam sim retomar seus verdadeiros e profundos significados, tal como a cidadania.

\section{COlETIVO de AUtORES E A CIDADANIA NAS AULAS de EduCAÇÃo FísıcA}

Como os próprios autores apontam, o livro "Metodologia do Ensino de Educação Física", publicado em 1992, tratava de uma pedagogia emergente, surgida no intuito de responder a determinados interesses de classe. Bem entendida a pedagogia como uma teorização sobre a educação referente a um determinado tempo histórico e sua pratica social; e um momento de crise pedagógica aquele em que as respostas construídas anteriormente já não convencem mais as pessoas de sua validade. Os fosse capaz de disputar espaço com as antigas pedagogias.

Outro entendimento que consideramos fundamental apresentar se refere ao projeto político-pedagógico. Para o Coletivo, ele representa uma intenção, uma vontade, é uma ação deliberada e estratégica e, por tanto, caminha na direção da pedagogia assumida 
pelo professor. Por isso mesmo, o nome político-pedagógico: político porque uma intervenção direcionada; e pedagógico porque reflete sobre a ação dos homens na realidade. Para os autores:

Todo educador deve ter definido o seu projeto político-pedagógico. Essa definição orienta a sua prática no nível da sala de aula: a relação que estabelece com seus alunos, o conteúdo que seleciona para ensinar e como trata científica e metodologicamente, bem como os valores e a lógica que desenvolve nos alunos. (COLETIVO DE AUTORES, 1992, p. 26) $)^{3}$.

Bem por isso, temos nos preocupado até o momento com questões de cunho filosófico: é a forma de entender e conceber o mundo, a educação, a escola, a cidadania, que garantirá ao educador os fundamentos para seu trabalho. Quando se parte de diferentes formas de se enxergar o mundo, por mais que os objetivos traçados sejam os mesmos, é muito difícil que os resultados sejam compatíveis. Defender aulas de educação físicas preocupadas com o desenvolvimento da cidadania é nosso foco central, mas é preciso destacar: de uma determinada cidadania, e não outras. Uma cidadania que não esteja atrelada ao consumo, e nem à garantia egoísta de amplos direitos para poucas pessoas. Mas uma cidadania caracterizada pela confirmação e ampliação dos direitos coletivos, em seus três âmbitos - civis, políticos e sociais.

A concepção de currículo ampliado trabalhado pelo Coletivo também nos é bastante interessante. Segundo os autores, todas as disciplinas de uma escola devem ser legitimadas pela necessidade que o aluno tem de, a partir dos conhecimentos referentes a cada área, construir seu entendimento sobre o mundo, sendo que nenhuma disciplina se justifica sozinha, mas é útil apenas como composição de um todo teórico. Há assim uma relação entre dois pólos: o todo -

${ }^{3}$ O livro "Metodologia de Ensino da Educação Física", escrito por Lino Castellani Filho, Carmen Lúcia Soares, Valter Bracht, Celi Taffarel, Micheli Escobar e Maria Elizabeth Varjal, e alcunhado pelos próprios de Coletivo de Autores teve sua $1^{\underline{a}}$ edição reimpressa 14 vezes, a última em 2008, já que em 2009 foi publicada sua $2^{\underline{a}}$ edição revista, hoje em sua $1^{\underline{a}}$ reimpressão. 
currículo - e as partes - disciplinas - donde surgem as práticas educacionais cotidianas, que o Coletivo chama de dinâmica escolar.

Tal entendimento sobre o currículo destaca uma responsabilidade da escola (talvez a maior delas) que vem sendo constantemente ignorada: ajudar ao aluno a desenvolver um entendimento cada vez mais amplo sobre o mundo que habita (espaço que influencia sua existência, e que também pode ser transformado pela existência do homem). Retomada a importância fundamental desse dever da escola, a educação física não poderia se justificar de forma alguma se atenta apenas ao aprimoramento e adestramento físico, ou mesmo ao necessário divertimento infantil. Só contribuirá para aprimorar o entendimento de mundo dos alunos a educação física fundamentada no trabalho com a cultura corporal. Esta, segundo o Coletivo, buscará:

Desenvolver uma reflexão pedagógica sobre o acervo de formas de representação do mundo que o homem tem produzido no decorrer da história, exteriorizadas pela expressão corporal: jogos, dança, lutas, exercícios ginásticos, esporte, malabarismo, contorcionismo, mímica e outros, que podem ser identificados como formas de representação simbólica de realidades vividas pelo homem, historicamente criadas e culturalmente desenvolvidas. (COLETIVO DE AUTORES, 1992, p. 38).

A fim de bem desenvolver tal processo, bem como qualquer outro, é preciso considerar que a dinâmica escolar está fundamentalmente relacionada, segundo o Coletivo, a três pólos: "[...] o trato com o conhecimento, a organização escolar e a normatização escolar" (COLETIVO DE AUTORES, 1992, p.29). Seria a forma de conceber e efetivar esses três tópicos uma questão fundamental para que um determinado objetivo educacional seja realizado. Sendo que, por vezes, tais pólos podem estar em concordância ou discordância, ou seja, a forma de planejar e transmitir o conhecimento pode caminhar na busca de um aluno autônomo, enquanto regras rígidas de comportamento, sustentadas através da punição, pode influenciar o aluno num sentido heterônomo. 
Se, como tem sido a maioria das críticas feitas ao Coletivo, professores vêm tendo dificuldade para trabalhar com essa concepção, acreditamos que o problema, diferente do que se possa imaginar a princípio, não está na falta de diretrizes e exemplos claros por parte do Coletivo de como dar uma aula crítico-superadora, mas sim na dificuldade, nas lacunas que ficaram no momento da fundamentação teórica dos professores, ou seja, na sua formação e no momento de apreensão do conteúdo do livro. Ou seja, é na retomada da fundamentação e do debate teórico que colocamos nossa esperança. É esse o intuito deste artigo: vinte anos depois da publicação do "Metodologia do Ensino de Educação Física", retomálo, rediscuti-lo, recolocá-lo em pauta para que a educação física brasileira enfim, tome os rumos que se desenham desde a década de 90. Atrelada não ao rigor militarista, ao "higienismo" médico, e nem mesmo ao consumismo interminável da atual organização social, mas sim a uma busca pela formação do cidadão consciente e crítico, capaz de transformar o mundo em que vive. 
School and Education for Citizenship: what is the role of physical education?

Abstract: This article discusses the relation between citizenship, which has been very present on the agenda in recent years, with school education. It presents a critique both of the understanding of citizenship concept and of its relationship with education, since the existing literature has sometimes been unadvised in doing so. Based on this discussion, this paper builds initial reflections on the possibility of physical education to contribute to the much-vaunted and sought formation of the citizen.

Keywords: Citizenship. Education. Physical Education.

\begin{abstract}
Escuela y Educación para la Ciudadanía: ¿cuál es el papel de la educación física?

Resumen: En este artículo se discute la relación entre la ciudadanía, que ha estado muy presente en la agenda en los últimos años, con la educación escolar. Se presenta una crítica tanto a la comprensión del concepto de ciudadanía como a su relación con la educación, ya que la literatura existente a veces ha sido descuidada al hacerlo. Con base en esta discusión, este documento se basa en reflexiones iniciales sobre la posibilidad de la educación física para contribuir a tan cacareada y buscado formación de los ciudadanos.

Palabras clave: Ciudadanía. Educación. Educación Física.
\end{abstract}

\title{
REFERÊNCIAS
}

ARROYO; M.;BUFFA, E; NOSELLA, P. Educação e cidadania: quem educa o cidadão? 8. ed. São Paulo: Cortez, 2000.

BENEVIDES, M. V. M. Cidadania e Democracia, Lua Nova, n. 33, p. 5-16, 1994.

CARVALHO, J. M. Cidadania no Brasil: o longo caminho. 13.ed. Rio de Janeiro: Civilização Brasileira, 2010. 
CASTELLANI FILHO, L. Educação Física no Brasil: a história que não se conta. Campinas: Papirus, 1988.

COLETIVO DE AUTORES. Metodologia do Ensino de Educação Física. São Paulo: Cortez, 1992.

DAGNINO, E. Políticas culturais, democracia e o projeto neoliberal. Revista Rio de Janeiro, Rio de Janeiro, n.15, p. 45-65, 2005.

DEMO, P. Cidadania tutelada e cidadania assistida. São Paulo: Autores Associados, 1995.

HOFLING, E. M. A concepção de cidadania veiculada em livros didáticos de estudos sociais do primeiro grau. Dissertação de mestrado, Campinas: Faculdade de Educação/Unicamp, 1981.

INSTITUTO PAULO MONTENEGRO. Indicador de Analfabetismo Funcional: Dados do Inaf. São Paulo. Disponível em: <http://www.ipm.org.br/ index.php?mpg=1.01.00.00.00\&ver=por>. Acesso em: 04 mar. 2012.

MARSHALL, T. H. Cidadania, Classe Social e Status. Rio de Janeiro: Zahar, 1967.

BRASIL. Constituição (1988). Constituição da República Federativa do Brasil. Brasília, DF: Senado, 1988.

BRASIL. MINISTÉRIO DA EDUCAÇÃO. Dados sobre a expansão da rede federal de educação profissional. Disponível em: <http://redefederal.mec.gov.br/ index.php?option=com_content\&view=article\&id=52\&ltemid=2>.. Acesso em: 04 mar. 2012.

NAGLE, J. Educação e Sociedade na Primeira República. São Paulo: EPU, 1974.

SEVERINO, A. J. A escola e a construção da cidadania. In: SEVERINO, A. J. et al. Sociedade civil e educação. Campinas: Papirus; São Paulo: Ande, 1992.

Financiamento: CNPq

Endereço para correspondência:

Flávio Cremasco Ferreira

Rua Luiza R. Brandini, 320.

Castelo, Valinhos - SP.

Recebido em: 21.08.2012

Aprovado em: 31.10.2012 